\title{
О ПРОМЕЖУТОЧНОМ УРОВНЕ АРАБСКОГО ЯЗЫКА В УСЛОВИЯХ ДИГЛОССИИ (НА ПРИМЕРЕ ЕГИПТА)
}

\section{ON THE INTERMEDIATE LEVEL OF THE ARABIC LANGUAGE IN TERMS OF DIGLOSSIA (ON THE EXAMPLE OF EGYPT)}

\section{Zakryzhevskiy}

Summary: The linguistic situation in Egypt, as in any other Arab country, is characterized by the presence of the phenomenon of diglossia, that is, in the linguistic community, there are simultaneously two varieties of the language - Literary Arabic Language, in English-language literature it is known as Modern Standard Arabic, and Egyptian Spoken Language (Egyptian Colloquial Arabic). This invariably raises the question of the possible existence of one or more intermediate levels of the language. The purpose of this article is to consider the existing concepts of intermediate levels of the Arabic language and, using the example of Egypt, to identify the causes and mechanisms of their formation, as well as the peculiarities of their use. The factors influencing the degree of proficiency at each of the levels among different segments of the population will be considered, as well as trends in the linguistic behavior of the Egyptians will be analyzed.

Keywords: diglossia, Modern Standard Arabic, spoken language of Egypt, language of the educated.

\section{Ранние коншепшии Аиглоссии}

$\mathrm{T}$ ермином «диглоссия» («di»-«два», «glossa» - «язык») изначально обозначалась языковая ситуация в Греции, где в качестве письменного языка и языка формального общения использовалась разновидность языка под названием «katharevousa», а для повседневной неформальной коммуникации использовалась несколько так называемых «народных» разновидностей языка - «dimotiki».

Диглоссию необходимо отличать от билингвизма, под которым понимается употребление в обществе двух разных языков, тогда как в ситуации диглоссии используемые вариации относятся к одному и тому женациональному языку.

Первым, кто применил понятие диглоссии к арабскому языку, был французский арабист Вильям Марсе, в начале 20 века консультировавший французскую колониальную администрацию в Северной Африке по вопросам языка. Марсе обозначил две местные разновидности арабского языка как «литературный/письменный арабский язык» и «язык разговорных идиом/разговорный арабский язык» [7, с. 402]. По его мнению, первая
Закрыжевский Максим Шакирович

Аспирант, Московский Государственный Университет имени М.В. Ломоносова desh9292@list.ru

Аннотация: Языковая ситуация в Египте, как и в любой другой арабской стране, характеризуется наличием явления диглоссии, то есть в языковом сообществе параллельно существуют две разновидности языка - Литературный Арабский Язык (ЛАЯ), в англоязычной литературе он известен как Modern Standard Arabic, и Египетский Разговорный Язык (Egyptian Colloquial Arabic). При этом неизменно встает вопрос о возможном существовании одного или нескольких промежуточных уровней языка. Цель данной статьи - рассмотреть существующие концепции промежуточных уровней арабского языка, и, на примере Египта, выявить причины и механизмы их формирования, а также особенности употребления. Будут рассмотрены факторы, влияющие на степень владения каждым из уровней среди разных слоев населения, а также проанализированы тенденции в языковом поведении египтян.

Ключевые слова: диглоссия, литературный арабский язык, разговорный язык Египта, язык интеллигенции.

разновидность обслуживает исключительно письменную сферу, а вторая действует только в сфере неформального общения.

С развитием печати стали публиковаться тесты, написанные тем самым языком идиом, о котором говорил Марсе, таким образом, разговорный язык стал проникать в письменную сферу. Со временем на основе разговорного языка стали возникать новые литературные жанры, и четкая граница между разновидностями, которая лежала в основе концепции диглоссии, стала размываться. Одновременно письменный язык стал активно использоваться в устной форме, особенно, в административной и образовательной сферах. Картина диглоссии, которая изначально была предельно ясна, значительно усложнилась, открыв простор для дальнейших, более детальных исследований.

\section{Базовая коншепция Фергюсона (1959 г.)}

Следующим важным шагом в понимании арабской диглоссии стала теория, выдвинутая Чарльзом Фергюсоном в ставшей классической работе «Diglossia». Одним из четырех определяющих примеров языковых сообществ, для которых характерна диглоссия, стал арабский 
мир. Кроме этого, Фегрюсон рассмотрел языковую ситуацию в современной Греции, немецкоязычных кантонах Швейцарии и на Гаити. В отличие от Марсе, Фергюсон разделил две разновидности языка не на письменный и устный, а на «высокий» (язык «H») и «низкий» (язык «L»).

В своем исследовании Фергюсон сосредоточил внимание на восьми основных аспектах употребления языков «H» и «L»:

1. Функциональное распределение: каждая из разновидностей языка имеет свою сферу употребления, которые пересекаются лишь частично. Для «высокого» языка (Н) это - проповеди в церквях и мечетях, речи политического характера (например, в парламенте), выпуски новостей, язык печатных СМИ. Для «низкого языка» (L) Фергюсон приводит следующее: обращение к обслуживающему персоналу, рабочим и мелким служащим, разговоры внутри семьи, а также с друзьями и коллегами, фольклор. Вместе с тем Фергюсон отмечает, что около 20\% пословиц и поговорок находятся в сфере «высокого» языка.

2. Фактор престижности: во всех рассматриваемых языках разновидность «Н» рассматривается носителями как более престижная, чем «L». Учитывая тот факт, что «высокий» язык осваивается в процессе получения высшего образования, говорящий, стремясь продемонстрировать свой образовательный уровень, пользуется литературным языком. Еще одним важной особенностью языка «Н» является его близость к сакральному языку священных текстов. Греческий литературный язык идентичен языку Нового Завета. Аналогична ситуация с литературным арабским языком, который максимально близок к классическому арабскому языку Корана.

3. Литературное наследие: на каждом из рассматриваемых языков существует огромный корпус литературных текстов, которые имеют очень высокий статус в рамках языкового сообщества. Это литературное наследие формировалось долгое время, и является источником лексики для современных авторов. Употребление этих элементов из классических текстов на языке «Н» в рамках литературной или журналистской деятельности рассматривается как признак хорошего владения языком и высокого профессионального мастерства.

4. Освоение языка: родным языком для членов каждого из рассматриваемых языковых сообществ является исключительно язык «L». Более формализованный и сложный для освоения язык «Н» изучается в школах и вузах, и, как правило, степень владения им среди носителей остается ниже, чем степень владения языком «L», языком повседневной жизни и бытового общения.
5. Традиция: язык «Н» является основой для богатой грамматической традиции, которая формируется столетиями и включает грамматические трактаты, словари, труды по фонетике, стилистике и риторике. Существуют устоявшиеся грамматическая, фонетическая и орфографическая нормы. Что касается языка «L», то таких норм либо не существует вовсе, либо они стали складываться относительно недавно, и представлены не так широко.

6. Грамматика: язык «Н» содержит грамматические категории, которые для языка «L» не характерны. Например, в литературном арабском языке есть три словоизменительные формы для слов именного класса и глаголов имперфекта, а в разговорных языках словоизменительных форм не существует.

7. Лексикон: одной из характерных особенностей диглоссии является существование разных лексем, употребляемых для передачи одного и того же значения в рамках языков «Н» и «L». Так, например, в разговорных арабских диалектах не употребляется глагол [ra'ā] (видеть), распространенный в литературном. Вместо него используется глагол [shāf] с тем же значением. Примечательно, что [shāf] существует во всех без исключения арабских диалектах, что делает его характерной чертой именно разговорной речи.

8. Фонетика: исходя из того, что язык «L» является для членов языкового сообщества родным, Фергюсон предполагает, что звуковые системы «Н» и «L» составляют единую фонологическую структуру, в которой фонология «L» является основной системой, а не соответствующие ей особенности фонологии «Н» являются либо подсистемой, либо парасистемой.

Опираясь на эти аспекты двуязычия, Фергюсон определяет диглоссию как языковую ситуацию, при которой, помимо одного или нескольких разговорных языков, в рамках языкового сообщества существует более сложная разновидность языка, сложившаяся на основе письменной литературной традиции более раннего периода, используемая в качестве письменного языка или языка формального общения.

Теория Фергюсона вызвала в научном сообществе некоторые вопросы, в частности, существуют ли между разновидностями «H» и «L» какие-либо промежуточные уровни.

Подходы к промежуточным уровням языка и выравнивание разговорных языков (Levelling)

Современная социолингвистика отмечает тенденцию смещения разных подуровней разговорных языков в сторону одного, более престижного. Это может быть 
язык крупного города, как предлагал Фергюсон, или язык определенной социальной группы - как правило, это образованные люди, чья разговорная речь становится примером для подражания и, своего рода, общим знаменателем для разных разговорных языков внутри сообщества. Учитывая тот факт, что люди стремятся с одной стороны сделать свою речь менее формализованной, более живой и свободной, а с другой стороны подчеркнуть свой социальный статус и принадлежность к интеллектуальной элите, своим ориентиром они выбирают именно такой, достаточно «высокий», но в то же время неформальный язык. Такой процесс в западной социолингвистике получил называние «языковое выравнивание» (Levelling - англ.). То есть, язык «L» не смещается ближе к языку «Н», а внутри разных подуровней языка «L» превалирующим становится более престижный. В арабской социолингвистике такое выравнивание породило несколько концепций промежуточных уровней языка, так называемоro «lugha wusțā» («средний язык» - араб.), сочетающего в себе черты литературного арабского языка и разговорного диалекта. При этом «lugha wusțā» не принадлежит ни языку «H», ни к языку «L».

\section{Разговорный язык образованного населения (Educated Spoken Arabic)}

Влияние уровня образования на языковое поведение носителей демонстрирует концепция разговорного арабского языка образованного населения [7, с.7-8] («Educated Spoken Arabic» - англ.) как разговорного языка образованных арабов, который является основным средством междиалектной коммуникации, поскольку он понятен носителям разных диалектов в силу схожих уровней образования. В его основе лежит словарный состав ЛАЯ, который является общим для носителей разных разговорных языков, кроме того, в ESA присутствуют элементы разговорного языка, общие для всех региональных диалектов (чаще всего фонетические).

При этом ESA не является промежуточным уровнем между ЛАЯ и разговорным языком, а играет роль наддиалектной разновидности языка, не привязанной к местному разговорному языку ни одной арабской страны. В концепции разговорного арабского языка образованного населения наибольший интерес представляет идея о том, что арабы из разных стран, носители разных разговорных языков, имея достаточно высокий уровень образования, при общении друг с другом меняют свой язык, создавая некое подобие общеарабского разговорного языка. В то же время данная концепция вызывает ряд вопросов: во-первых, само по себе понятие образованного населения является недостаточно четким: идет ли речь о функционально грамотных людях или же о людях с определенным культурным уровнем? Во-вторых, функционирование разновидностей арабского языка даже в границах одной страны всё еще представляет сложность для исследователей. Как в этом случае описать правила, по которым строится коммуникация представителей разных языковых сообществ? До сих пор не удалось определить, как именно функционирует ESA, поэтому само его существование вызывает сомнения у ряда исследователей [2, с.16].

\section{Коншепчия Бамави м^я Египта}

В 1973 году египетский лингвист Мухаммад Бадави выдвинул свою концепцию промежуточных языковых уровней. Рассматривая языковую ситуацию в Египте, он предложил следующую многоступенчатую схему:

- Классический арабский («fușḥa al-turāth»). Язык арабского классического наследия. Самый высокий уровень языка в рамках языкового сообщества Египта.

- Современный литературный арабский («fușḥa al'аșr»). Литературная форма арабского языка (ЛАЯ), использующаяся при письме и иногда в формальной речи.

- Язык интеллигенции («'ammiyat al-muthaqqafīn»). Формальный разговорный язык образованного населения. На него серьезное влияние оказывает ЛАЯ.

- Язык грамотных («'ammiyat al-mutanawwirīn»). Разговорный язык людей, получивших базовое образование (не университетское). Используется в разговорах на бытовые темы (спорт, мода). Иногда звучит на телевидении.

- Разговорный неграмотного населения. ('ammiyat al-ummiyīn»). Вообще не подвержен влиянию литературного языка, так как необразованное население им не владеет.

Предложенная Бадави схема показывает, что литературный и разговорный языки в Египте неоднородны, и каждый из них имеет свои подуровни.

Уровни 1 и 2 соответствуют «высокому» языку («Н») в теории Фергюсона, уровни 4 и 5 - «низкому» языку. Уровень 3 является переходным между ними, тем самым «полуформальным» языком. Бадави проводит границу, на которой кончается литературный язык и начинается разговорный: уровни 1 и 2 он обозначил как «fușhā», тогда как уровень 3 - уже «'ammiуyа». Объясняет он это следующим образом: на уровне 2 встречаются некоторые фонологические черты разговорного языка, но морфологическая и синтаксическая структура соответствует литературной норме. На уровне 3 достаточно часто употребляется лексика литературного языка, который влияет также и на фонологическую характеристику речи, однако, синтаксическая структура высказываний, в частности, порядок слов, согласование. выражение аспектуальности и наклонения соответствуют разговорному языку. Уровни 1 и 2 качественно отличаются от уровней 3-5, тогда как последние три уровня отличаются друг от 
друга количественно, то есть, по частотности использования разговорных элементов.

Терминология Бадави свидетельствует и о том, что уровни «'ammiуyа» отличаются по социальному статусу людей, которые ими оперируют, а два уровня «fușhā» противопоставляют наследие прошлого и современность. Исходя из этого, данная концепция отражает и различие стилей (продиктованных тематикой), и языковое поведение разных социальных слоев. Вместе с тем Бадави ясно дает понять, что носители языка никогда не оперируют лишь одним уровнем, во всяком случае, образованные люди. В зависимости от тематики разговора, каирцы могут задействовать уровни 3, 4 и 5 (хотя уровень 5 будет, скорее всего, задействован при общении с неграмотными собеседниками). Переходить на уровень 2 в устной речи египтянам нет необходимости, если только это не входит в их профессиональные обязанности (например, такие, как работа на телевидении, выступление с докладами на конференциях). Впрочем, они сталкиваются с ним каждый день, так как он транслируется средствами массовой информации.

В концепции Бадави наибольшее внимание исследователей привлекает уровень 3, который является переходным от литературного арабского языка к разговорному, и характерные особенности которого все еще недостаточно изучены.

\section{"Язык интемиигеншии» как наиболее яркий пример промежуточного уровня языка}

Бадави описывает «язык интеллигенции» как уровень, на котором отступление от нормы литературного языка настолько сильно, что становится невозможным утверждать, что речь все еще остается в рамках «аlfușḥā». На самом же деле, если сравнить примеры высказываний на литературном языке и соответствующие им варианты на «языке интеллигенции», то выясняется, что разница между двумя уровнями состоит только в немногочисленных особенностях (чаще всего, лексических и фонетических), относящихся либо к «fușhāa al-'așr», либо К «'ammiyat al-muthaqqafinn» [1, c.148].

Бадави приводит мнение знаменитого египетского писателя Тауфика ал-Хакима, который говорил о формировании «третьего языка»: сравнивая два предложения [al-arbāḥ dī tamma tawzi'hā bi-n-nisba li-aghlab il'ummāl] и [hādhihi-I- arbāḥ dī tamma tawzi'uhā bi-n-nisba li-aghlab al-'ummāl], он отмечает, что ярким свидетельством перехода на уровень «al-'ammiуа» является употребление указательного местоимения [dī] и его расположение в постпозиции к существительному [al-arbāḥ]. Тауфик ал-Хаким считает это «точкой невозврата на пути от литературного арабского языка к разговорного египетскому [1, с.149].
Если же таких очевидных маркеров нет, то, по мнению Бадави, определить, к какой разновидности языка или уровню языка относится та или иная фраза, часто не представляется возможным, даже если она содержит в себе некоторые разговорные черты.

Продолжая рассматривать «язык интеллигенции», Бадави утверждает, что этот уровень представляет собой границу, до которой доходит «аl-'ammiya» «в своем движении вверх по направлению к «fușḥā al-'așr», и на которой он получает возможность «устно выражать современную культуру» [1, с.149]. Этот язык используется образованными людьми при обсуждении тем, связанных с культурой, искусством или наукой, то есть, он несет ту же культурную функцию (gharaḍ), что и литературный язык, но если ЛАЯ - это язык письменный, и свободно оперировать им в устной речи могут немногие, то его функции в сфере устного общения принимает на себя «язык интеллигенции» [1, с.150].

Таким образом, по мнению Бадави, «'ammiyat almuthaqqafīn» является альтернативой литературному языку в устной речи. Необходимость рассуждать на культурные и научно-технологические темы, чего не позволяет делать разговорный язык в силу ограниченности словарного фонда и особенностей стилистики, заставила подавляющее большинство образованных египтян создать особую разновидность языка. Эта разновидность сочетает в себе разговорные и литературные характеристики, точнее, те литературные характеристики, которые доступны им для обозначения терминологии и выражения абстрактного значения, а также те черты разговорного языка, которыми они свободно владеют, а именно морфологическая структура слов и синтаксическая структура предложений. В результате образовался тот язык, который сегодня известен как «язык интеллигенции». Иными словами, его появление было вызвано насущной необходимостью описания современного общества и культуры [1, с.151].

Бадави утверждает, что на этом уровне говорящий чувствует максимальную свободу при выражении своих мыслей, не будучи ограниченным правилами и нормами письменного литературного языка, он может погрузиться в самые сложные темы, не беспокоясь о грамотности своей речи.

\section{Городской язык как универсальный стандарт}

Появление такого промежуточного уровня в рамках арабской диглоссии в немалой степени обусловлено ростом городского населения, а также ростом уровня грамотности в арабских странах. Города привлекают молодежь из сельских районов возможностью получить образование и работу, и ролевой моделью для этих молодых людей становятся интел- 
лектуалы, предпочитающие изъясняться на разговорном языке с элементами литературного, именно такой язык и распространяется в крупных городах. В частности, в Египте каирский вариант разговорного языка считается наиболее универсальным. Язык Каира является ориентиром для носителей различных региональных диалектов, поскольку сам город является центром притяжения и символом высокого уровня жизни. Исходя из этого, можно предположить, что в рамках диглоссии есть тенденция сближения не между языками «L» и «H», а между разговорным языком интеллигенции крупных городов и говорами египетской провинции [4, с.338]. Это заставляет нас заново взгля- нуть на предложенную Фергюсоном схему. Выясняется, что реальная картина арабской диглоссии не только более обширна и сложна, но и скрывает тенденцию к популяризации городских разговорных языков.

Подводя итог, можно сказать, что промежуточные уровни между «Н» и «L» действительно имеют место. Кроме того, наблюдается тенденция к «выравниванию» разговорных языков на базе языка городских интеллектуалов, который представляет собой разговорный язык, в котором широко представлены элементы литературного. Причем эти элементы могут встречаться не только на фонетическом, но и на лексическом уровне.

\section{ЛИТЕРАТУРА}

1. Badawi, as-Said Muhammad, Mustawayāt al-'arabiyya al-mu'āsira fi Mișr, Dār al ma'ārif, 1973

2. Bassiouney R. Modern Arabic Socioliguistics. Edinburgh, 2009

3. Ferguson, C.A., Diglossia. Word 15, 1959. 325-340

4. Gunvor M., Diglossia. Arrabic Political Discourse Analysis. Routledge, 2018

5. Hinds M., Badawi S., A dictionary of Egyptian Arabic: Arabic-English. Beirut, 1986

6. Lentin, J., Reflections on Middle Arabic. In: G. Mejdell and L. Edzard, eds. High vs. low and mixed varieties: status, norms and functions across time and languages. Wiesbaden: Harrassowitz Verlag, 2012

7. Marçais, W., La diglossie arabe. L'Enseignement Public - Revue Pédagogique, 104 (12), 401-409, 1930

8. Mitchell, T.F. What is educated spoken Arabic. International Journal of the Sociology of Language 61, 1986. 7-32 